K. HOLLANDERS, E. RENDERS, C. GADAIS, D. MASUlLO, L. VAN RAEMDONCK, C. C.

D. WYBON, C. MARTIN, W. A. HERREBOUT, B. U. W. MAES*, S. BALLET* (VRIJE

UNIVERSITEIT BRUSSEL AND UNIVERSITY OF ANTWERP, BELGIUM)

Zn-Catalyzed Nicotinate-Directed Transamidations in Peptide Synthesis

ACS Catal. 2020, 10, 4280-4289.

\section{Zinc-Catalyzed Peptide Synthesis by Using a Nicotinate-Directed Protocol}

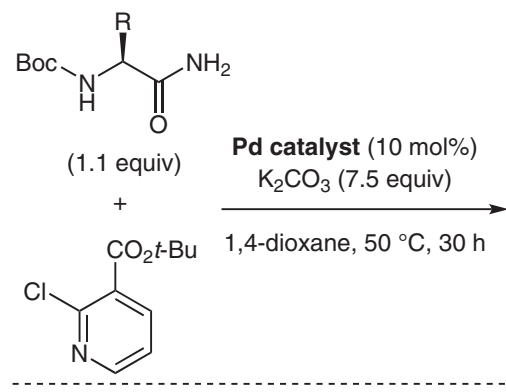<smiles>CC(C)(C)OC(=O)NC(P)C(=O)Nc1ncccc1C(=O)OC(C)(C)C</smiles>

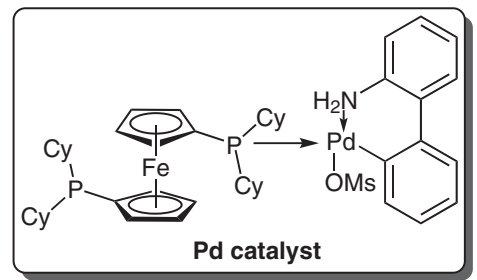

Preparation of nic amino acid amides:<smiles>CCCCOC(=O)c1cccnc1NC(=O)C(C)NC(C)(C)C</smiles><smiles>O=C(NC(Cc1ccccc1)C(=O)Nc1ncccc1C(=O)OCc1ccccc1)c1ccccc1</smiles><smiles>CC(C)(C)OC(=O)c1cccnc1NC(=O)C1CCCN1C(=O)OC(C)(C)C</smiles><smiles>[R7]C(Nc1ncccc1C(=O)NC(C)(C)C)C(=O)NC(C)(C)CC</smiles>

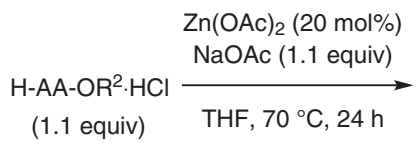<smiles>[R7]C(=O)C([R7])NC(=O)C([R7])NC(=O)OCc1ccccc1</smiles>

Selected examples:

Boc-L-Phe-L-Phe-OMe $95 \%$ yield
Boc-L-Ala-L-Leu-OAll $99 \%$ yield
Boc-L-Pro-L-Leu-OMe $95 \%$ yield
Boc-L-Met-L-Trp-OBn $80 \%$ yield<smiles>CCCOCC[C@H](NC(=O)OCc1ccccc1)C(=O)N[C@@H](C)C(=O)Nc1ncccc1C(=O)OC(C)(C)C</smiles>

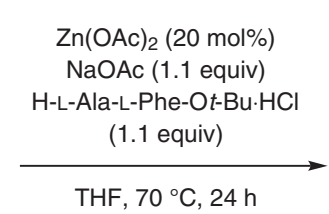

THF, $70^{\circ} \mathrm{C}, 24 \mathrm{~h}$<smiles>CCCCOC(=O)C(Cc1ccccc1)NC(=O)C(C)NC(=O)[C@H](C)NC(=O)C(CCOCC)NC(=O)OCc1ccccc1</smiles>

$74 \%$ vield
Significance: Development of new systems for peptide-bond formation is an ongoing challenge to organic chemists. The authors report a new strategy using tert-butyl nicotinate amino amides, formed from amino acids and tert-butyl 2-chloronicotinate with palladium catalysis, as excellent nucleophiles for the synthesis of dipeptides.
Comment: Various tert-butyl nicotinate amino amides were smoothly generated in high yields and high enantioselectivities. The products and amino acid ester $\mathrm{HCl}$ salts were easily converted into the corresponding dipeptides by using zinc catalysis. Furthermore, this protocol can also be applied in the synthesis of tripeptides.

\section{Key words}

zinc catalysis

palladium catalysis

butylnicotinate amino amides

directing group

transamidation 